\title{
A Portable System for Remote Rehabilitation Following a Total Knee Replacement: A Pilot Randomized Controlled Clinical Study
}

\author{
Kevin M. Bell ${ }^{1,2,3, *}$, Chukwudi Onyeukwu ${ }^{1}$, Clair N. Smith ${ }^{1}$, Adrianna Oh ${ }^{1}$, \\ Annette Devito Dabbs ${ }^{4}$, Sara R. Piva ${ }^{5}$, Adam J. Popchak ${ }^{5}{ }^{\circ}$, Andrew D. Lynch ${ }^{5}$, \\ James J. Irrgang ${ }^{1,5}$ and Michael P. McClincy ${ }^{1}$ \\ 1 Department of Orthopaedic Surgery, School of Medicine, University of Pittsburgh, Pittsburgh, PA 15213, \\ USA; Onyeukwu.Chukwudi@medstudent.pitt.edu (C.O.); CNS45@pitt.edu (C.N.S.); \\ oh.adrianna@medstudent.pitt.edu (A.O.); jirrgang@pitt.edu (J.J.I.); mcclincymp@upmc.edu (M.P.M.) \\ Department of Bioengineering, Swanson School of Engineering, University of Pittsburgh, Pittsburgh, \\ PA 15213, USA \\ 3 Clinical and Translational Science Institute, University of Pittsburgh, Pittsburgh, PA 15213, USA \\ 4 Department of Acute and Tertiary Care, School of Nursing, University of Pittsburgh, Pittsburgh, PA 15213, \\ USA; ajdst42@pitt.edu \\ 5 Department of Physical Therapy, School of Health and Rehabilitation Sciences, University of Pittsburgh, \\ Pittsburgh, PA 15213, USA; spiva@pitt.edu (S.R.P.); ajp64@pitt.edu (A.J.P.); adl45@pitt.edu (A.D.L.) \\ * Correspondence: kmb7@pitt.edu; Tel.: +412-383-6914
}

Received: 15 May 2020; Accepted: 23 October 2020; Published: 27 October 2020

\begin{abstract}
Rehabilitation has been shown to improve functional outcomes following total knee replacement (TKR). However, its delivery and associated costs are highly variable. The authors have developed and previously validated the accuracy of a remote (wearable) rehabilitation monitoring platform (interACTION). The present study's objective was to assess the feasibility of utilizing interACTION for the remote management of rehabilitation after TKR and to determine a preliminary estimate of the effects of the interACTION system on the value of rehabilitation. Specifically, we tested post-operative outpatient rehabilitation supplemented with interACTION $(\mathrm{n}=13)$ by comparing it to a standard post-operative outpatient rehabilitation program $(n=12)$ using a randomized design. Attrition rates were relatively low and not significantly different between groups, indicating that participants found both interventions acceptable. A small (not statistically significant) decrease in the number of physical therapy visits was observed in the interACTION Group, therefore no significant difference in total cost could be observed. All patients and physical therapists in the interACTION Group indicated that they would use the system again in the future. Therefore, the next steps are to address the concerns identified in this pilot study and to expand the platform to include behavioral change strategies prior to conducting a full-scale randomized controlled trial. Trial registration: ClinicalTrials.gov NCT02646761 "interACTION: A Portable Joint Function Monitoring and Training System for Remote Rehabilitation Following TKA" 6 January 2016.
\end{abstract}

Keywords: interactive health technologies; remote rehabilitation; total knee replacement

\section{Introduction}

Knee osteoarthritis (OA) is a chronic condition [1] and the leading cause of pain and disability in older adults [2,3]. If conservative treatments do not relieve symptoms, a total knee replacement (TKR) is frequently recommended. In 2010, 719,000 TKR surgeries were performed in the United States and the number of annual TKRs is projected to double or triple over the next 20-30 years [4,5]. TKR represents 
the highest aggregate cost among rapidly increasing surgical procedures $[6,7]$. The rapidly increasing number of TKRs and their associated cost threaten to impose an enormous economic burden on the healthcare system in the United States and around the world. In an attempt to combat these rising costs, the Centers for Medicare and Medicaid Services (CMS) introduced the Comprehensive Care for Joint Replacement (CJR) Model in 2016, which proposes a bundled payment model [8]. Unlike fee-for-service payment models, bundled payments incentivize value-based care wherein providers use coordinated, multidisciplinary healthcare approaches to enhance quality, efficiency, and patient satisfaction while controlling costs [9].

Cost analyses have shown that post-acute care accounts for the greatest cost variation in the TKR episode of care $[10,11]$, thus post-acute care is the most logical target for cost savings under the bundled care model [12]. Rehabilitation is a major component of post-acute care with significant cost and relevance to functional outcomes. Rehabilitation has been shown to improve functional outcomes following TKR [13-16]. However, its delivery and associated costs are highly variable [17]. Inadequate rehabilitation can lead to longer recovery, further injury from improper performance, and increased downstream costs, so its costs must be minimized while ensuring its effective delivery $[18,19]$.

The current status quo of physical therapy delivery has notable limitations. A nationwide shortage of physical therapists is projected, limiting in-person access as demand increases [20]. Access is further impaired by mobility and income limitations such as transportation issues, inability to handle copays, and low health literacy [21-25]. Even in optimal settings, the majority of rehabilitative work is done through home exercise. However, non-adherence with the prescribed home exercise regimen may be as high as $70 \%$ [26-28] and the factors contributing to non-adherence are multifactorial. Early evidence suggests that tele-rehabilitation and/or remote rehabilitation using mobile health technologies has the potential to overcome these barriers and improve access, accountability, and value [29-39].

The authors have developed and previously validated the accuracy [40] of a remote rehabilitation monitoring platform (interACTION) that uses portable inertial measurement units (IMUs) combined with a mobile application and back-end clinician portal. The present study's objective was to assess the feasibility of utilizing interACTION for remote management of rehabilitation after TKR and to determine a preliminary estimate of the effects of the interACTION system on the value of rehabilitation. Value was operationally defined as the change in the Activities of Daily Living Scale (ADLS) of the Knee Outcome Survey divided by the cost of rehabilitation. Specifically, we tested post-operative outpatient rehabilitation supplemented with interACTION by comparing it to a standard post-operative outpatient rehabilitation program using a randomized design.

\section{Materials and Methods}

\subsection{Overview}

This study has been registered with ClinicalTrials.gov (NCT02646761). This was a two-group pilot randomized clinical study implemented from June 2016 to September 2017 in the UPMC Centers for Rehab Services (CRS, Pittsburgh, PA, USA). We enrolled male and female subjects between the ages of 40 and 80 years who were scheduled to undergo a primary unilateral TKR and who had been referred for post-operative outpatient physical therapy at a UPMC CRS facility. Exclusion criteria were bilateral or revision TKR; patients who had a pre-operative referral to a skilled nursing facility or were transferred to a skilled nursing facility for post-operative care; patients with BMI $>40$ at the time of surgery; individuals who were not free of any other co-disability or comorbidity that would specifically hinder performance of rehabilitation exercises; and individuals who could not understand/utilize the audio and visual feedback from the system.

\subsection{Recruitment and Consent}

Subjects scheduled to receive a TKR at a UPMC facility were recruited pre-operatively at Orthopedic Surgery clinics or the pre-operative educational session that is required for all patients. The research 
coordinator fully explained the study, checked for eligibility, and then recruited patients. The University of Pittsburgh Institutional Review Board approved the study protocol (PRO15060281). All participants provided written informed consent before conducting any research procedures.

\subsection{Randomization}

The randomization sequence was computer-generated in block sizes of 4,6 , and 8 . Allocation was sealed in opaque and consecutively numbered envelopes. The research coordinator pre-operatively randomized to one of two groups: standard post-operative outpatient rehabilitation (Control Group) or interACTION Group.

\subsection{Interventions}

In the Control Group, patients performed their post-operative outpatient rehabilitation in the clinic with a physical therapist. Patients visited/attended the clinic for two to three sessions per week, over a maximum of 10 weeks and supplemented with a home exercise program. To help maximize generalizability, physical therapists were asked to treat the patient according to the standard "best practices" for post-operative outpatient rehabilitation.

In the interACTION Group, post-operative outpatient rehabilitation was performed in the clinic with a physical therapist and supplemented with interACTION to remotely manage the home exercise program. For the first two weeks, patients used inter ACTION during the routine outpatient rehabilitation clinic sessions to familiarize themselves with the system. Patients were then issued an interACTION device for home use. Over eight weeks, participants in the interACTION Group continued to return to the outpatient rehabilitation facility but were asked to reduce their number of weekly visits to the outpatient facility by one visit per week while concurrently using interACTION at home.

\subsection{Device Description}

InterACTION (University of Pittsburgh Ref: 03425, 04275) utilizes portable motion sensors placed on either side of a joint and attached with adjustable neoprene straps (Figure 1-Left), to collect joint orientation data using a custom mobile application (Figure 1-Middle). A more thorough description of the technical parameters of the motion sensors has been published previously [36]. The mobile application contains 30 knee-specific home exercises for TKR rehabilitation. The physical therapist creates a personalized home exercise program from these exercises and can offer remote guidance through the clinician portal (Figure 1-Right).

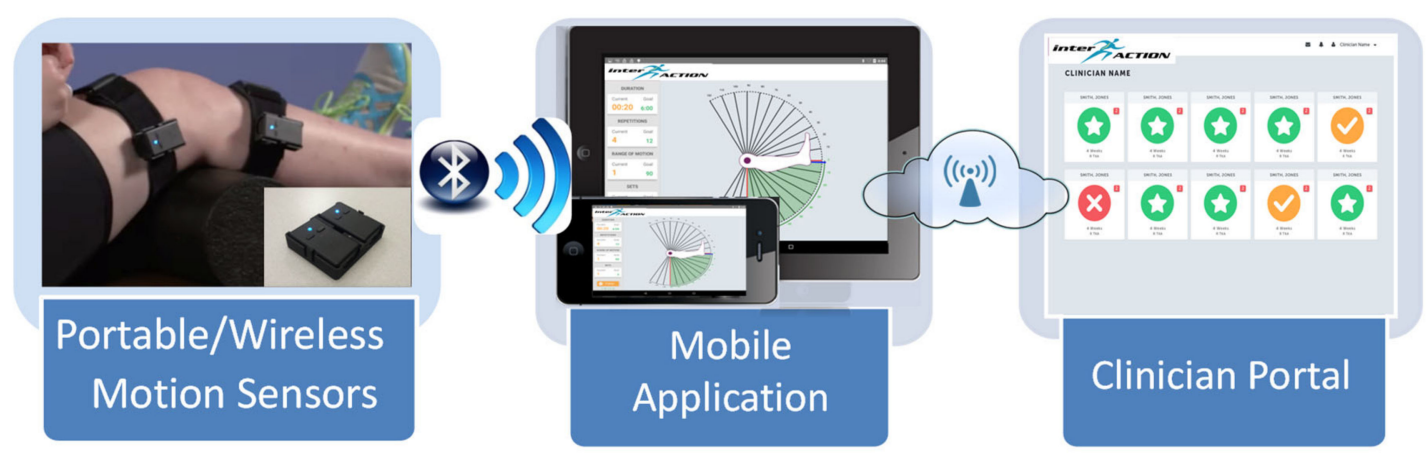

Figure 1. Conceptual flowchart of the interACTION platform: (1) inertial measurement units (IMUs) attached to the patient's thigh and shank using neoprene straps and 3D-printed cases, (2) mobile application utilized by the patient to complete their prescribed home exercises, (3) screenshot of clinician portal depicting the patient dashboard which is utilized by the physical therapist to manage the patient's rehabilitation remotely.

A written description and video demonstration are provided for each exercise. Before the patient performs their exercises, the mobile application guides them through a series of recovery metrics 
to assess their progress. The patient then uses the interface to complete the prescribed exercises. The motion data are analyzed to provide real-time feedback to the patient.

The feedback utilizes on-screen animation of knee motion and a color-coded feedback mechanism to inform the patients if they are outside (red), approaching (yellow), or have reached (green) the target range of motion for their exercise. When the feedback indicator turns yellow, the system automatically increments the "attempted repetition counter" and when the indicator turns green the system automatically increments the "successful repetition counter." This two-tiered approach allows the physical therapist to determine if the patient performed the exercises correctly.

The adherence and recovery data collected in the mobile application are automatically synchronized, using a wireless connection, to a web-based clinician portal. The clinician portal utilizes a dashboard to enable the physical therapist to monitor multiple patients simultaneously and identify patients needing personalized attention. The physical therapist can remotely refine a treatment plan using the portal, which automatically synchronizes with the mobile application used by the patient. The clinician portal also has built-in communication options that enable the physical therapist to contact the patient directly.

\subsection{Clinical Measures}

Outcome assessment was carried out by the research coordinator who was not blinded to the group assignment. Assessments were performed at baseline (first post-operative outpatient rehabilitation visit) and at 5 weeks ( \pm 7 days) and 10 weeks ( \pm 7 days) from baseline.

The feasibility of the interventions was assessed by adherence to the home exercise sessions (Control Group), device usage (interACTION Group), loss to follow-up, and attrition. Control Group participants were asked to record their daily performance of the prescribed home exercises on a paper-based exercise log. InterACTION Group participants were asked to use interACTION daily to guide them through their home exercise program.

The primary outcome was value, which was operationally defined as the change in the Activities of Daily Living Scale (ADLS) of the Knee Outcome Survey at 10 weeks divided by the total cost of rehabilitation. The ADLS is a 14-item measure of symptoms and activity limitations for individuals with a variety of knee impairments [41,42]. The cost of rehabilitation was determined based on the billing records of the CRS physical therapy facility, which is a function of the total number of physical therapy sessions and the billable charges for each session during the 10 weeks the patients were enrolled in the study.

The following secondary outcome measures were collected at baseline and 5-week and 10-week follow-ups: active range of motion (aROM) [43], in which ROM was calculated as the difference between maximum flexion and maximum extension, measured with a standard goniometer while the patient lies in the supine position; the Numeric Pain Rating Scale (NPRS), which asks participants to rate their pain levels currently and their level of worst and least pain in the past $24 \mathrm{~h}$ on a scale from 0 (no pain) to 10 (worst pain imaginable); and the Veterans RAND 12-Item Health Survey (VR-12), a 12-item patient-reported general measure of health-related quality of life [44].

Functional performance was tested in all patients at the 5-week and 10-week timepoints using a battery of four performance-based tests: (1) the six-minute walk test $[45,46]$, which assesses the distance the subject is able to walk over a period of six minutes; (2) the stair climbing test [47], in which a patient ascends and descends a standard flight of stairs as quickly and safely as possible; (3) the timed up and go test (TUG) [48], in which the patient sits in a standard armed chair, rises, walks three meters, turns around, walks back to the chair, and sits; and (4) the unilateral balance test $[45,46]$, in which the patient attempts to maintain single leg balance for up to two minutes. The functional performance tests were not performed at baseline due to the fact that the baseline testing occurred too close to surgery.

At the 10-week assessment, the research coordinator conducted a semi-structured interview with all patients in the interACTION Group and their physical therapists to query about their experiences 
with rehabilitation and the interACTION platform via a combination of survey questions, a self-reported assessment of adherence, and open-ended discussion questions.

\subsection{Sample Size Determination}

Given the nature of the funding source and timeframe for completion of the study, the sample size was limited to a total of 60 subjects ( 30 per group). Assuming a one-tailed test with an alpha of 0.05 , a total sample size of 60 patients (30 per group) enabled us to detect a medium to large effect (standardized mean difference of 0.65 ) in value. The statistical justification presented is based on historical data, which may or may not be reflective of the population recruited in this study.

\subsection{Statistical Analyses}

A modified intention-to-treat analysis was implemented in this study. No data were excluded from the analysis based on a participant's level of adherence or device usage. However, only participants who completed baseline testing were included in the analysis. All data that were available for all participants were included in the analysis, and no attempt was made to approximate the missing data points.

A Wilcoxon rank-sum test was used to compare the primary outcome (value) measures between groups. The alpha value was set at $\alpha=0.05$ for all outcomes. A Wilcoxon rank-sum test was also used to compare cost analyses parameters (weeks of physical therapy, number of physical therapy visits, total time, and total cost) between the two groups.

For the feasibility analysis, adherence and device usage were calculated as the percentage of the total number of exercise sessions recorded between weeks 3 through 10 relative to a total of 40 possible exercise sessions over the 8-week period (assuming 5 sessions per week). Loss to follow-up was calculated as the number of participants randomized to each group minus the number of participants that completed the baseline assessment. Attrition was calculated as the number of participants that completed baseline testing, but did not complete the 10-week assessment, divided by the number of subjects that completed the baseline assessment.

For the ADLS and aROM (flexion), a repeated measures ANOVA or a two-sample $t$-test was used to compare differences between groups if the distribution was normal. A Wilcoxon rank-sum test was used for non-normally distributed data.

The functional performance tests were assessed at the 5- and 10-week visits, using an averaged z-score (or standard score) to calculate a cumulative score for the six-minute walk (distance in feet), stair climbing (time divided by steps), TUG (time), and unilateral balance (time) tests [49]. On average, the z-scores were close to zero, meaning the scores for each individual subject did not differ from the mean score across all subjects. Differences between the cumulative z-scores were assessed using a repeated measures ANOVA or a two-sample $t$-test was used to compare differences between groups if the distribution was normal. A Wilcoxon rank-sum test was used for non-normally distributed data.

The semi-structured patient and physical therapist interviews were transcribed and analyzed by a qualitative data analysis team (Qualitative, Evaluation and Stakeholder Engagement [Qual EASE] Research Services, Center for Research on Health Care Data Center, University of Pittsburgh) unaffiliated with the research team, to minimize the potential for bias. The Qual EASE team developed a qualitative coding scheme that enabled all responses to be categorized as criticisms, affirmations, or suggestions. The qualitative coding was then completely co-coded and fully adjudicated by two independent Qual EASE analysts.

\section{Results}

We screened 47 people for participation in this study. Nine were deemed ineligible and 38 individuals were randomized (mean [SD] age; 64.4 [8.2], 48\% female) (Figure 2). Of the 19 individuals randomized to the Control Group and 19 randomized to the interACTION Group, 12 individuals in the Control Group and 13 in the interACTION Group completed baseline assessment post-operatively. 
Seven participants in the Control Group and six in the interACTION Group were unable to complete baseline testing after randomization. Attrition did not differ between the groups at 10 weeks: values were $16.6 \%$ ( 2 of 12) in the Control Group and 23.0\% (3 of 13) in the interACTION Group. Baseline characteristics were similar between groups (Table 1 ).

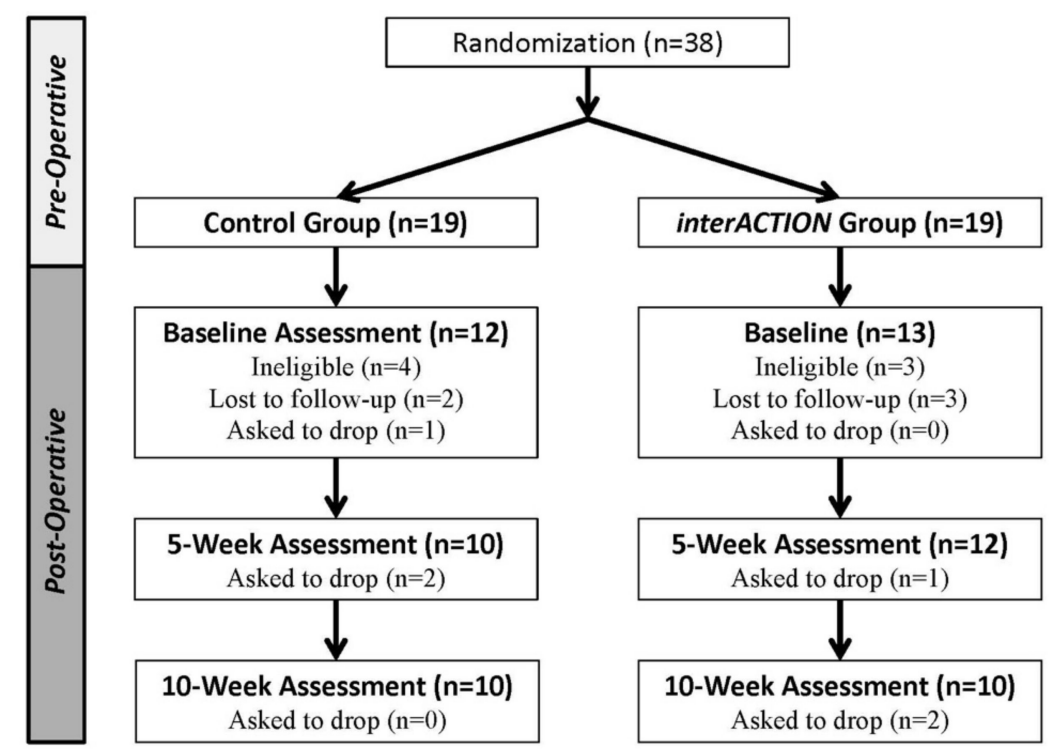

Figure 2. Consolidated standards of reporting trials (CONSORT) diagram of participant flow during the study.

Table 1. Participant characteristics at baseline.

\begin{tabular}{|c|c|c|c|}
\hline & $\begin{array}{c}\text { Total } \\
(n=38)\end{array}$ & $\begin{array}{l}\text { Control } \\
(n=19)\end{array}$ & $\begin{array}{l}\text { interACTION } \\
\quad(\mathrm{n}=19)\end{array}$ \\
\hline Age (mean \pm SD) & $64.4 \pm 8.2$ & $65.3 \pm 8.3$ & $64.0 \pm 7.7$ \\
\hline BMI (mean \pm SD) & $31.0 \pm 5.2$ & $31.1 \pm 5.2$ & $31.8 \pm 5.7$ \\
\hline Female & $18(47 \%)$ & $9(47 \%)$ & $9(47 \%)$ \\
\hline \multicolumn{4}{|l|}{ Race } \\
\hline White & $32(84 \%)$ & $16(89 \%)$ & $16(89 \%)$ \\
\hline Black & $5(13 \%)$ & $2(11 \%)$ & $3(16 \%)$ \\
\hline Hispanic ethnicity & $1(3 \%)$ & $1(5 \%)$ & $0(0 \%)$ \\
\hline Married & $25(66 \%)$ & $11(58 \%)$ & $14(74 \%)$ \\
\hline \multicolumn{4}{|l|}{ Education } \\
\hline Some high school & $1(3 \%)$ & $1(5 \%)$ & $0(0 \%)$ \\
\hline High school grad & $8(21 \%)$ & $4(21 \%)$ & $4(21 \%)$ \\
\hline Some college & $7(18 \%)$ & $6(32 \%)$ & $1(5 \%)$ \\
\hline College graduate school & $10(26 \%)$ & $4(21 \%)$ & $6(32 \%)$ \\
\hline Some graduate school & $3(8 \%)$ & $2(11 \%)$ & $1(5 \%)$ \\
\hline Graduate degree & $9(24 \%)$ & $2(11 \%)$ & $7(37 \%)$ \\
\hline \multicolumn{4}{|l|}{ Employment status } \\
\hline Retired due to health & $4(10 \%)$ & $2(11 \%)$ & $2(11 \%)$ \\
\hline Retired not due to health & $17(44 \%)$ & $8(42 \%)$ & $9(47 \%)$ \\
\hline Temporary retired due to health & $3(8 \%)$ & $1(5 \%)$ & $2(11 \%)$ \\
\hline Semi-retired & $1(3 \%)$ & $0(0 \%)$ & $1(5 \%)$ \\
\hline Regular full time & $11(29 \%)$ & $7(37 \%)$ & $4(21 \%)$ \\
\hline Regular part time & $2(5 \%)$ & $1(5 \%)$ & $1(5 \%)$ \\
\hline Current Smoker & $4(10 \%)$ & $3(16 \%)$ & $1(5 \%)$ \\
\hline
\end{tabular}




\subsection{Value}

The primary outcome was value-calculated as the ratio of change in ADLS from baseline to 10 -week follow-up divided by the total cost of physical therapy. Considering the parameters individually, no difference could be detected in delta ADLS (Control: 33.6 [13.9], interACTION: 30.5 [13.1], $p=0.555$ ) or total cost (Control: USD 2231 [USD 1255], interACTION: USD 2452 [USD 1160], $p=0.67$ ) (Table 2). Similarly, for value (delta ADLS/total cost), no difference could be detected between groups (Control: 0.018 [0.009], interACTION: 0.013 [0.007], $p=0.32$ ].

Table 2. Value analysis.

\begin{tabular}{cccc}
\hline & $\begin{array}{c}\text { Control } \\
(\mathbf{n}=\mathbf{1 0})\end{array}$ & $\begin{array}{c}\text { interACTION } \\
(\mathbf{n}=\mathbf{1 0})\end{array}$ & $p$-Value \\
\hline Weeks of PT & $8.1 \pm 3.2$ & $7.3 \pm 2.3$ & 0.48 \\
Number of PT visits & $13.3 \pm 5.5$ & $12.7 \pm 5.1$ & 0.71 \\
Total time (minutes) & $786 \pm 411$ & $828 \pm 394$ & 0.69 \\
Total cost & $\$ 2231 \pm \$ 1255$ & $\$ 2452 \pm \$ 1160$ & 0.67 \\
Delta ADLS/\# visits & $3.0 \pm 1.6(8)$ & $2.4 \pm 1.0(8)$ & 0.45 \\
Value (Delta ADLS/total cost) & $0.018 \pm 0.009(8)$ & $0.013 \pm 0.007(8)$ & 0.32 \\
\hline
\end{tabular}

\subsection{Adherence}

One of the primary goals of interACTION was to increase adherence to home exercise. During the 10-week semi-structured interviews, all participants were asked to self-report their level of adherence. One participant in the control group failed to complete the self-reported adherence question, reducing the sample size $n=9$. Self-reported rates of adherence were similar between groups, with five out of nine individuals in the Control Group reporting $>90 \%$ adherence and 6 out of 10 individuals in the interACTION Group reporting $>90 \%$ adherence (Table 3). Participants in the Control Group also completed a paper-based exercise log, which showed 50\% [37\%] adherence over the 10-week period. Participants in the interACTION Group were not asked to complete an exercise log. Device usage was calculated as a surrogate measure of adherence and determined to be $37 \%$ [24\%] between week 3 and week 10 .

Table 3. Self-reported compliance.

\begin{tabular}{|c|c|c|c|}
\hline \multicolumn{4}{|c|}{ How Compliant Were You on Average with the Rehabilitation Process? } \\
\hline$(\%)$ & $\begin{array}{c}\text { Total } \\
(\mathrm{n}=19)\end{array}$ & $\begin{array}{l}\text { InterACTION } \\
\quad(\mathrm{n}=10)\end{array}$ & $\begin{array}{c}\text { Control } \\
(\mathrm{n}=9)\end{array}$ \\
\hline$>90 \%$ & $11(61 \%)$ & $6(60 \%)$ & $5(63 \%)$ \\
\hline $71-90 \%$ & $7(33 \%)$ & $4(40 \%)$ & $3(25 \%)$ \\
\hline $51-70 \%$ & $0(0 \%)$ & $0(0 \%)$ & $0(0 \%)$ \\
\hline $31-50 \%$ & $1(6 \%)$ & $0(0.0)$ & $1(13 \%)$ \\
\hline $0-30 \%$ & $0(0 \%)$ & $0(0 \%)$ & $0(0 \%)$ \\
\hline
\end{tabular}

\subsection{Secondary Outcomes}

The study was not powered to detect differences in the secondary clinical and functional performance outcome measures. However, the feasibility of collecting the secondary outcomes at baseline, 5 weeks, and 10 weeks was established in this pilot study with no more than one missing data point observed for any of the secondary clinical or functional performance outcome measures at any time point (Table 4). Preliminary analysis showed no detectable significant differences for any of the secondary outcome measures at any time point, with the exception of NPRS within the last $24 \mathrm{~h}$, when measured at 10 weeks, which indicated higher pain levels in the interACTION Group compared to the Control Group (Control: 2.2 [2.5], interACTION: 3.7 [1.9], $p=0.043$ ). 
Table 4. Clinical and physical function outcomes over time in study arms ( $t$ - two-sample $t$-test, $w$-Wilcoxon rank-sum test, $\left.{ }^{*}-p<0.05\right)$. The sample size for each outcome is also provided (n), with any reduced sample size compared to Figure 2 indicating missing data. The functional performance outcomes were not measured at baseline because the timepoint was too close to surgery.

\begin{tabular}{|c|c|c|c|c|c|}
\hline & Control & (n) & interACTION & (n) & $p$-Value \\
\hline \multicolumn{6}{|l|}{ ADLS } \\
\hline Baseline & $48.7 \pm 17.5$ & (12) & $46.5 \pm 11.6$ & (11) & 0.835 \\
\hline 5-Week & $70.7 \pm 15.3$ & (10) & $66.7 \pm 14.8$ & (12) & 0.559 \\
\hline 10-Week & $83.1 \pm 13.8$ & (9) & $76.9 \pm 13.9$ & (10) & 0.474 \\
\hline Delta (10-Week - Baseline) & $33.6 \pm 13.9$ & (9) & $30.5 \pm 13.1$ & (10) & 0.555 \\
\hline \multicolumn{6}{|l|}{ VR-12 } \\
\hline Baseline & $27.1 \pm 7.8$ & (11) & $26.3 \pm 12.1$ & (12) & 0.923 \\
\hline 5-Week & $35.9 \pm 7.8$ & (10) & $39.4 \pm 10.3$ & (11) & 0.457 \\
\hline 10-Week & $43.5 \pm 9.0$ & (10) & $42.2 \pm 5.8$ & (9) & 0.898 \\
\hline Delta (10-Week - Baseline) & $17.4 \pm 11.7$ & (10) & $16.0 \pm 12.6$ & (9) & 0.972 \\
\hline \multicolumn{6}{|l|}{$\begin{array}{l}\text { Numeric Pain Rating Scale } \\
\text { (NPRS) } 24 \text { Hours }\end{array}$} \\
\hline Baseline & $5.7 \pm 3.1$ & (12) & $5.6 \pm 2.4$ & (13) & $0.963^{t}$ \\
\hline 5-Week & $3.0 \pm 2.2$ & (10) & $3.1 \pm 1.7$ & (12) & $0.920^{t}$ \\
\hline 10-Week & $2.2 \pm 2.5$ & (10) & $3.7 \pm 1.9$ & (10) & $0.043^{w}$ \\
\hline Delta (10-Week - Baseline) & $-3.5 \pm 3.0$ & (10) & $-2.2 \pm 2.5$ & $(10)$ & $0.308^{t}$ \\
\hline \multicolumn{6}{|l|}{ Active Extension (degrees) } \\
\hline Baseline & $1.1 \pm 3.4$ & (12) & $5.3 \pm 5.6$ & (13) & $0.067^{w}$ \\
\hline 5-Week & $1.7 \pm 3.0$ & (9) & $2.1 \pm 2.7$ & (12) & $0.773^{w}$ \\
\hline 10-Week & $1.7 \pm 2.5$ & (10) & $1.6 \pm 2.5$ & (10) & $0.878^{w}$ \\
\hline Delta (10-Week - Baseline) & $0.6 \pm 3.5$ & (10) & $-3.8 \pm 5.5$ & $(10)$ & $0.063^{w}$ \\
\hline \multicolumn{6}{|l|}{ Active Flexion (degrees) } \\
\hline Baseline & $91.5 \pm 19.3$ & (12) & $93.0 \pm 17.6$ & (12) & 0.810 \\
\hline 5-Week & $119.7 \pm 5.1$ & (9) & $116.7 \pm 12.0$ & (12) & 0.577 \\
\hline 10-Week & $123.1 \pm 4.9$ & (10) & $120.8 \pm 8.6$ & (10) & 0.737 \\
\hline Delta (10-Week - Baseline) & $31.4 \pm 21.8$ & (10) & $31.4 \pm 20.0$ & $(10)$ & 0.645 \\
\hline \multicolumn{6}{|l|}{$\begin{array}{l}\text { Unilateral Balance Test } \\
\text { (seconds) }\end{array}$} \\
\hline 5-Week & $34.4 \pm 36.3$ & (10) & $30.0 \pm 28.8$ & (12) & $0.770^{w}$ \\
\hline 10-Week & $50.0 \pm 35.4$ & (10) & $39.7 \pm 42.9$ & (10) & $0.256^{w}$ \\
\hline Delta (10-Week - 5-Week) & $15.6 \pm 28.6$ & (10) & $13.7 \pm 34.6$ & (10) & $0.577^{w}$ \\
\hline \multicolumn{6}{|l|}{ Timed Up and Go (seconds) } \\
\hline 5-Week & $9.7 \pm 3.1$ & (10) & $8.9 \pm 3.2$ & (12) & 0.562 \\
\hline 10-Week & $8.6 \pm 2.5$ & (10) & $8.6 \pm 3.1$ & (10) & 0.939 \\
\hline Delta (10-Week - 5-Week) & $-1.1 \pm 1.7$ & (10) & $-0.4 \pm 2.4$ & (10) & 0.482 \\
\hline \multicolumn{6}{|l|}{ Stair Climb Test (steps/second) } \\
\hline 5-Week & $0.6 \pm 0.2$ & (9) & $0.6 \pm 0.3$ & $(11)$ & 0.606 \\
\hline 10-Week & $0.7 \pm 0.3$ & (9) & $0.8 \pm 0.4$ & (10) & 0.855 \\
\hline Delta (10-Week - 5-Week) & $0.2 \pm 0.2$ & (9) & $0.1 \pm 0.2$ & (10) & 0.646 \\
\hline \multicolumn{6}{|l|}{6 Minute Walk (meters) } \\
\hline 5-Week & $384.8 \pm 93.0$ & (10) & $410.1 \pm 145.1$ & (12) & $0.820^{w}$ \\
\hline 10-Week & $445.8 \pm 86.6$ & (10) & $478.4 \pm 182.6$ & (9) & $0.904^{w}$ \\
\hline Delta (10-Week - 5-Week) & $60.9 \pm 56.5$ & (10) & $46.4 \pm 56.3$ & (9) & $0.582^{t}$ \\
\hline \multicolumn{6}{|l|}{ Composite Functional } \\
\hline 5-Week & $0.004 \pm 0.701$ & (10) & $0.006 \pm 0.932$ & (12) & $0.995^{t}$ \\
\hline 10-Week & $0.028 \pm 0.636$ & (10) & $-0.071 \pm 1.021$ & (10) & $0.797^{t}$ \\
\hline Delta (10-Week - 5-Week) & $-0.002 \pm 0.836$ & (10) & $0.099 \pm 0.851$ & (10) & \\
\hline
\end{tabular}

\subsection{Survey Results}

Analysis of the patient survey questions showed that three of the seven survey questions had a median score of 4 and the remaining four survey questions had a median score of 3 (Table 5). The sample size for the patient surveys was $n=11$, rather than $n=10$ as indicated in Figure 2, due to 
the fact that one of the participants that asked to be dropped from the study prior to the 10-week assessment still completed a survey. Generally, the majority of patients found the exercises relevant to their rehabilitation (median $=4$, interquartile range $[\mathrm{IQR}]=1$ ), the visual feedback easy to understand (median $=4, \mathrm{IQR}=2$ ), and forms of media (videos, text, motion feedback, etc.) useful (median = 4, $I Q R=1$ ). All eleven patients surveyed said that they would consider using interACTION in the future.

Table 5. Patient survey responses $(n=11)$.

\begin{tabular}{|c|c|c|c|c|c|c|c|}
\hline Patient Survey Responses $(\mathrm{n}=11)$ & 0 & 1 & 2 & 3 & 4 & Median & IQR \\
\hline $\begin{array}{l}\text { Were the exercises in interACTION relevant to your rehabilitation? } \\
\qquad(4-\text { very relevant })\end{array}$ & 0 & 1 & 0 & 3 & 7 & 4 & 1 \\
\hline $\begin{array}{l}\text { Does the screen layout and the structure of the app make it easy to } \\
\text { navigate? (4 - easiest) }\end{array}$ & 0 & 0 & 2 & 6 & 3 & 3 & 0.5 \\
\hline Is it easy to setup and calibrate the sensors for use? (4 - very easy) & 1 & 1 & 1 & 3 & 5 & 3 & 1.5 \\
\hline $\begin{array}{l}\text { Is the visual feedback from the app easy to understand? (4-very } \\
\text { easy to understand) }\end{array}$ & 0 & 1 & 3 & 1 & 6 & 4 & 2 \\
\hline $\begin{array}{l}\text { Are the forms of media (videos, text, motion feedback, etc.) useful? } \\
\qquad(4-\text { very useful })\end{array}$ & 1 & 0 & 1 & 2 & 7 & 4 & 1 \\
\hline $\begin{array}{l}\text { Are the angles shown during the exercises helpful in keeping track } \\
\text { of your recovery? (4 - very helpful) }\end{array}$ & 2 & 0 & 2 & 2 & 5 & 3 & 2 \\
\hline \multirow[t]{2}{*}{$\begin{array}{c}\text { Is indicating your pain levels helpful in keeping track of your } \\
\text { recovery? (4 - very helpful) }\end{array}$} & 3 & 0 & 2 & 3 & 3 & 3 & 2.5 \\
\hline & & & & & & Yes & No \\
\hline $\begin{array}{l}\text { Would you consider using the inter ACTION device if you had to } \\
\text { do rehabilitation again in the future? }\end{array}$ & & & & & & 11 & 0 \\
\hline
\end{tabular}

Of the $\mathrm{n}=10$ physical therapists in the interACTION group whose patients completed the 10-week assessment, $n=9$ were interviewed and $n=6$ completed the survey. Analysis of the physical therapist surveys showed that six of the ten survey questions had a median score of 4 and the remaining four survey questions had a median score of 3 or 3.5. Additionally, all six physical therapists surveyed indicated that they would consider using interACTION to manage rehabilitation again in the future (Table 6).

Table 6. Provider survey responses $(n=6)$.

\begin{tabular}{|c|c|c|c|c|c|c|c|}
\hline Provider Survey Responses $(n=6)$ & 0 & 1 & 2 & 3 & 4 & Median & IQR \\
\hline $\begin{array}{l}\text { Are all the exercises provided in the inter ACTION system } \\
\text { relevant and useful for rehabilitation? ( } 4 \text { - most relevant) }\end{array}$ & 0 & 0 & 1 & 2 & 3 & 3.5 & 1 \\
\hline $\begin{array}{l}\text { Does the screen layout and the calendar view make the } \\
\text { clinician portal easy to navigate? ( } 4 \text { - easiest) }\end{array}$ & 0 & 0 & 0 & 1 & 5 & 4 & 0 \\
\hline $\begin{array}{l}\text { Is it easy and convenient to modify and assign exercises to } \\
\text { the patient? ( } 4 \text { - very easy) }\end{array}$ & 0 & 0 & 1 & 2 & 2 & 3 & 1 \\
\hline $\begin{array}{c}\text { Is the visual feedback on the patient's progress easy to } \\
\text { understand? ( } 4 \text { - very easy to understand) }\end{array}$ & 0 & 0 & 0 & 1 & 4 & 4 & 0 \\
\hline $\begin{array}{l}\text { Are the forms of media (Patient Summary, Calendar View, } \\
\text { Graphs, etc.) used to review data on patient performance } \\
\text { and compliance useful? ( } 4 \text { - very useful) }\end{array}$ & 0 & 0 & 0 & 1 & 4 & 4 & 0 \\
\hline $\begin{array}{c}\text { Is the "Recovery Score" useful or helpful to keep track of } \\
\text { patient recovery? (4 - very helpful) }\end{array}$ & 0 & 0 & 0 & 3 & 2 & 3 & 1 \\
\hline $\begin{array}{l}\text { Is the "Range of Motion Tracking" graph useful or helpful } \\
\text { to keep track of patient recovery? (4 - very helpful) }\end{array}$ & 0 & 0 & 1 & 1 & 3 & 4 & 1 \\
\hline $\begin{array}{l}\text { Is the "Pain Levels Trends" graph useful or helpful to keep } \\
\text { track of patient recovery? ( } 4 \text { - very helpful) }\end{array}$ & 0 & 0 & 0 & 3 & 2 & 3 & 1 \\
\hline $\begin{array}{l}\text { Is the "Compliance Score" useful or helpful to keep track of } \\
\text { patient recovery? (4 - very useful) }\end{array}$ & 0 & 0 & 0 & 0 & 5 & 4 & 0 \\
\hline \multirow[t]{2}{*}{$\begin{array}{l}\text { Is the printout summary of patient progress useful or } \\
\text { helpful by giving a concise and comprehensive view of the } \\
\text { patient's progress? ( } 4 \text { - very helpful) }\end{array}$} & 0 & 0 & 0 & 0 & 2 & 4 & 0 \\
\hline & & & & & & Yes & No \\
\hline $\begin{array}{l}\text { Would you consider using the inter ACTION device to } \\
\text { manage rehabilitation again in the future? }\end{array}$ & & & & & & 6 & 0 \\
\hline
\end{tabular}


Qualitative analysis of the open-ended discussion questions indicated that answers from the patients and physical therapists frequently overlapped in terms of what they liked (affirmations), did not like (criticisms), and what they would like to see changed or improved (suggestions), with the interACTION system. The criticisms focused on the functionality of the equipment and the interface, while the affirmations focused on motivation and accountability, as well as the system's potential for future use.

The results of the patient interviews are summarized in Table 7. The sample size for the patient interview qualitative analysis was limited to $\mathrm{n}=7$ due to errors in the audio recording procedures. In total, 34 quotations across the seven patient interviews were coded as affirmations. With a few exceptions, patients felt that using the interACTION system or participating in the study gave them additional motivation or accountability to do their exercises. Specifically, six patients indicated that interACTION gave them motivation/accountability and four patients indicated that they found the visual feedback useful.

Table 7. Patient interviews $(n=7)$.

\begin{tabular}{lc}
\hline & Patient \#s \\
\hline Affirmations & 3,6 \\
Easy to use & $1,3,4,7$ \\
Feedback and/or media useful & 2,5 \\
Hastened rehab & $1,3,7$ \\
Helpful when working & $1,2,4,5,6,7$ \\
Gave motivation/accountability & $1,2,3,5,6$ \\
Other affirmation & \\
\hline Criticisms & $3,4,5,6,7$ \\
Calibration/counting errors & $1,3,5,7$ \\
Crashes or system failure & 5 \\
Demotivating when not working & 2 \\
Difficult to put on & 5,7 \\
Fit poorly & 3 \\
Learning curve & 1,7 \\
Limited feedback & 6,7 \\
Difficult to set up & $3,5,6$ \\
Other criticism & \\
\hline Suggestions & 5 \\
Allow provider to change order of exercises & 3,7 \\
Make setup faster (procedural) & $1,5,7$ \\
Improve the harness/straps (fit, stability, or comfort) & $1,3,5$ \\
Improve the user interface & 1,2 \\
Create better instructions & 7 \\
Include more ranges of motion & 4 \\
Include more exercises & 4 \\
Make exercises progressive for therapy & 7 \\
Other suggestions & \\
\hline
\end{tabular}

Thirty-eight quotations across the seven patient survey interviews were coded as criticisms. The main complaints were calibration and sensor issues and mobile application failures. Patient suggestions were more diverse than the criticisms or affirmations, though lower in occurrence, at 13 quotations counted across the seven transcripts. Suggestions included improving the user interface and the sensor harnesses and straps.

The number of affirmations (31 quotations) was roughly the same as the criticisms (29 quotations) across the nine provider interviews (Table 8). There was a wide variety of affirmations provided by the physical therapists, with five providers indicating that inter ACTION provided motivation/accountability and five indicating that the reports and tracking are useful. The most common criticism from providers was that the calibration or counting errors led to inconsistent measurements of range of motion, which 
frustrated the patients. There were fewer quotations in the provider interviews coded as suggestions than there were criticisms and affirmations, with only 10 coded across the nine transcripts. However, the number of unique suggestions was roughly commensurate with the unique complaints and points of praise. The suggestions made by the physical therapists could generally be described as addressing their own criticisms. The two most common suggestions were to improve the calibration of the sensors and simplify the setup for patients.

Table 8. Provider interviews $(n=9)$.

\begin{tabular}{lc}
\hline & Provider \#s \\
\hline Affirmations & \\
\hline Integrates well into clinic & $1,8,9$ \\
Easy to modify exercises & 10,11 \\
Feedback is good for the patient & $4,9,10$ \\
Provides motivation/accountability & $4,5,7,8,10$ \\
Improves patient outcomes & 1,10 \\
Portal is easy to use & 1,8 \\
System is self-contained & 10 \\
Reports and tracking are useful & $5,6,7,9,10$ \\
Exercises are useful & 8,10 \\
Other affirmation & $1,6,10$ \\
\hline Criticisms & \\
Calibration/count errors & $1,5,6,8,9,10$ \\
Difficult to change order of exercises & 8 \\
Not enough exercises included & 6,7 \\
Portal layout is confusing & 10 \\
Patient difficulty and frustration & $4,5,6,8,10$ \\
Setup (initial/clinical) is difficult & $4,5,10$ \\
Other criticism & $6,10,11$ \\
\hline Suggestions & \\
Simplify the system for patient & 7,10 \\
Give audio/voice feedback to patient & 1,6 \\
Count "partial" exercises & 6 \\
Increase accuracy & 5,10 \\
Include more exercises & 10 \\
Sense more ranges of motion & 5,10 \\
Improve harness, make sleeve & \\
Create tutorials & \\
\hline & \\
\hline
\end{tabular}

\section{Discussion}

This study assessed the feasibility of utilizing interACTION for remote management of rehabilitation after TKR and estimated the effects of the interACTION system on the "value" of rehabilitation. Specifically, we tested post-operative outpatient rehabilitation supplemented with interACTION by comparing it to a standard post-operative outpatient rehabilitation program using a randomized design.

The original sample size estimation indicated that we needed to recruit a total of 60 subjects (30 per group). However, due to the nature of the funding source and the timeframe for completion of the study, recruitment was terminated after 38 subjects were enrolled. Feedback from participants in the interACTION group, both informally throughout the study period and during the 10-week semi-structured interviews, indicated that although participants were very optimistic about the concept and potential for interACTION, they experienced functionality and usability issues that hindered the impact of the intervention. Therefore, the decision was made to stop recruitment before originally planned, and utilize the feedback from the interACTION participants as a component (field test) of a user-centered design process [50]. A sample size of 38 was sufficient to assess the feasibility of the 
study design. Preliminary analysis of the primary and secondary clinical outcomes was also conducted and presented.

Baseline feasibility characteristics were similar between groups, indicating that the computer-generated randomization scheme was effective. The attrition rates were relatively low and not significantly different between groups, indicating that participants found both interventions acceptable. We did observe a relatively high loss to follow-up between recruitment and baseline testing. The primary reason for this loss was that participants were no longer eligible ( 7 of 13$)$, because they either went to a skilled nursing facility post-operatively or elected to receive physical therapy at a non-UPMC CRS facility. An additional 5 of the 13 patients could not be contacted post-operatively. This study design limitation should be addressed in future trials by revising the exclusion criteria so that recruitment begins post-operatively to eliminate the gap in contact, or by beginning baseline testing and intervention pre-operatively to ensure that patients engage with the platform prior to surgery.

Additionally, the participants in the interACTION Group were asked to reduce the number of weekly visits by one visit per week after their two-week training period. This instruction was ultimately left to the discretion of the physical therapist and patient. Although a small (not statistically significant) decrease in number of physical therapy visits was observed in the interACTION Group, the effect was not as large as anticipated and no significant difference in total cost could be observed. It was unexpected that the average costs in the interACTION Group were slightly higher than the Control Group. However, subsequent analysis of the individual CPT codes revealed a single outlier in each group that accounted for this difference. As a result, no difference in the value, the primary outcome, could be detected. After feasibility and efficacy have been established, future cost-effectiveness trials should place tighter restrictions on the number of visits if value is the primary outcome.

We were unable to detect any consistently significant differences in the secondary clinical and functional performance outcomes measures, with the exception of NPRS within the last $24 \mathrm{~h}$, which was higher at 10 weeks in the interACTION Group. Future work is required to determine if this observation is a result of the small sample size or if the interACTION intervention negatively impacted pain levels.

To date, the most directly comparable studies were published by Piqueras et al. [29] and Correia et al. [30]. Piqueras et al. evaluated the effectiveness of a virtual telerehabilitation system, comprising nine degree-of-freedom wireless kinematic sensors, in patients after total knee replacement [29]; the primary outcome was function, assessed with the active range of knee movement. They determined that a two-week interactive telerehabilitation program was at least as effective as conventional therapy. Similarly, Correia et al. presented a home-based rehabilitation platform that included digital biofeedback using inertial motion trackers to digitize patient motion and provide real-time feedback on performance through a mobile application [30]. They completed an eight-week feasibility study, using TUG as the primary outcome, and concluded that their digital rehabilitation solution achieved better outcomes than conventional in-person rehabilitation. Several studies have explored the effectiveness of traditional telerehabilitation [31,32] using activity monitors [33-35] or other motion sensing technologies to facilitate the delivery of home exercises [36-39,51].

We conducted semi-structured interviews with the physical therapists and patients assigned to the interACTION Group at the 10-week assessment. Qualitative analysis of the participants enabled us to evaluate their experiences with the interACTION platform and to identify areas for improvement. Criticisms seemed to coalesce around a few central themes. Both patients and providers noted that the functionality and usability of interACTION could be improved. Patients became frustrated and even demotivated when they experienced connectivity issues or when the sensors' readings were variable, especially in regard to exercise repetition counts. Some providers felt the system did not give them reliable compliance information.

Suggestions from both groups corresponded with their criticisms and included fixing technical problems, improving hardware functionality, and increasing features and options. The more novel suggestions focused on the desire to expand the technology to empower the patient to take a more active role in their own recovery. Therefore, future work should explore the possibility of incorporating 
behavioral change strategies that have been shown to be effective in promoting adherence and sustaining behavioral change into the platform [52-56].

Patients and providers also generally agreed, with few exceptions, that if the complaints were addressed and suggestions carried out in a future iteration, interACTION would be very useful on both ends of care. Therefore, the next steps are to address the functionality and usability concerns identified in this pilot study and to expand the platform to include behavioral change strategies prior to conducting a full-scale randomized trial to evaluate the utility of the platform.

Author Contributions: Conceptualization, K.M.B., A.D.L., J.J.I., and M.P.M.; Data curation, K.M.B., C.O., A.O., A.D.L., and A.J.P.; Formal analysis, K.M.B., C.N.S., A.D.D., A.J.P., J.J.I., and M.P.M.; Funding acquisition, K.M.B., A.D.L., J.J.I., and M.P.M.; Investigation, K.M.B., C.O., C.N.S., A.O., A.D.D., S.R.P., A.J.P., A.D.L., J.J.I., and M.P.M.; Methodology, K.M.B., A.D.D., S.R.P., A.D.L., J.J.I., and M.P.M.; Project administration, K.M.B., C.O., A.D.L.; Supervision, J.J.I. and M.P.M.; Writing-original draft, K.M.B.; Writing-review and editing, K.M.B., C.O., C.N.S., A.O., A.D.D., S.R.P., A.J.P., A.D.L., J.J.I., and M.P.M. All authors have read and agreed to the published version of the manuscript.

Funding: We gratefully acknowledge the research funding support for this project provided through the University of Pittsburgh Coulter Translational Research Partners II Program (PI: Sanjeev Shroff), the Pittsburgh Innovation Challenge (Under the CTSI parent grant \#UL1TR000005, PI: Steven Reis), and the University of Pittsburgh PCOR Career Development Program (K12 HS 022989-01, PI: Wishwa Kapoor).

Acknowledgments: The study sponsors had no role in the study design, collection, analysis or interpretation of data; in the writing of the manuscript; or in the decision to submit the manuscript for publication. I would also like to acknowledge Jessa Darwin and Ethan Lennox for the editorial support that they provided during the preparation of this manuscript.

Conflicts of Interest: Kevin Bell, Michael McClincy, Andrew Lynch, and James Irrgang have financial interest with interACTION (University of Pittsburgh Reference \#04275) being evaluated in this research study. This means that it is possible that the results of this study could lead to personal profit for the individual investigator(s) and/or the University of Pittsburgh.

\section{References}

1. Losina, E.; Katz, J.N. Total joint replacement outcomes in patients with concomitant comorbidities: A glass half empty or half full? Arthritis Rheum. 2013, 65, 1157-1159. [CrossRef] [PubMed]

2. Song, J.; Chang, R.W.; Dunlop, D.D. Population impact of arthritis on disability in older adults. Arthritis Rheum. 2006, 55, 248-255. [CrossRef] [PubMed]

3. Spiers, N.A.; Matthews, R.J.; Jagger, C.; Matthews, F.E.; Boult, C.; Robinson, T.G.; Brayne, C. Diseases and impairments as risk factors for onset of disability in the older population in England and Wales: Findings from the Medical Research Council Cognitive Function and Ageing Study. J. Gerontol. A Biol. Sci. Med. Sci. 2005, 60, 248-254. [CrossRef] [PubMed]

4. Kurtz, S.M.; Ong, K.L.; Schmier, J.; Zhao, K.; Mowat, F.; Lau, E. Primary and revision arthroplasty surgery caseloads in the United States from 1990 to 2004. J. Arthroplast. 2009, 24, 195-203. [CrossRef] [PubMed]

5. Inacio, M.C.S.; Paxton, E.W.; Graves, S.E.; Namba, R.S.; Nemes, S. Projected increase in total knee arthroplasty in the United States-An alternative projection model. Osteoarthr. Cartil. 2017, 25, 1797-1803. [CrossRef] [PubMed]

6. HCUP Fast Stats-Most Common Operations During Inpatient Stays. Available online: https://hcup-us.ahrq.gov/faststats/NationalProceduresServlet?year1=2015\&characteristic1=0\&included1= 1\&year2=2008\&characteristic $2=54 \&$ included2 $=1 \&$ expansionInfoState $=$ hide $\&$ dataTablesState $=$ hide\& definitionsState $=$ hide\&exportState $=$ hide $($ accessed on 16 May 2019).

7. Gilbert, H.T.J.; Hodson, N.; Baird, P.; Richardson, S.M.; Hoyland, J.A. Acidic pH promotes intervertebral disc degeneration: Acid-sensing ion channel -3 as a potential therapeutic target. Sci. Rep. 2016, 6, 37360. [CrossRef] [PubMed]

8. Hogan, C.A.; Sandoval, M.F.; Uhler, L.M. Centers for Medicare \& Medicaid Services' Comprehensive Care for Joint Replacement: The Present and Future for Orthopedic Surgeons. Orthopedics 2017, 40, 77-80. [CrossRef]

9. McLawhorn, A.S.; Buller, L.T. Bundled Payments in Total Joint Replacement: Keeping Our Care Affordable and High in Quality. Curr. Rev. Musculoskelet Med. 2017, 10, 370-377. [CrossRef]

10. Bozic, K.J.; Ward, L.; Vail, T.P.; Maze, M. Bundled payments in total joint arthroplasty: Targeting opportunities for quality improvement and cost reduction. Clin. Orthop. Relat. Res. 2014, 472, 188-193. [CrossRef] 
11. Navathe, A.S.; Troxel, A.B.; Liao, J.M.; Nan, N.; Zhu, J.; Zhong, W.; Emanuel, E.J. Cost of Joint Replacement Using Bundled Payment Models. JAMA Intern. Med. 2017, 177, 214-222. [CrossRef]

12. Slover, J.D. You Want a Successful Bundle: What About Post-discharge Care? J. Arthroplast. 2016, 31, 936-937. [CrossRef] [PubMed]

13. Moffet, H.; Collet, J.P.; Shapiro, S.H.; Paradis, G.; Marquis, F.; Roy, L. Effectiveness of intensive rehabilitation on functional ability and quality of life after first total knee arthroplasty: A single-blind randomized controlled trial. Arch. Phys. Med. Rehabil. 2004, 85, 546-556. [CrossRef] [PubMed]

14. LaStayo, P.C.; Meier, W.; Marcus, R.L.; Mizner, R.; Dibble, L.; Peters, C. Reversing muscle and mobility deficits 1 to 4 years after TKA: A pilot study. Clin. Orthop. Relat. Res. 2009, 467, 1493-1500. [CrossRef]

15. Valtonen, A.; Poyhonen, T.; Sipila, S.; Heinonen, A. Effects of aquatic resistance training on mobility limitation and lower-limb impairments after knee replacement. Arch. Phys. Med. Rehabil. 2010, 91, 833-839. [CrossRef]

16. Piva, S.R.; Gil, A.B.; Almeida, G.J.; DiGioia, A.M., III; Levison, T.J.; Fitzgerald, G.K. A balance exercise program appears to improve function for patients with total knee arthroplasty: A randomized clinical trial. Phys. Ther. 2010, 90, 880-894. [CrossRef]

17. Mechanic, R. Post-acute care-the next frontier for controlling Medicare spending. N. Engl. J. Med. 2014, 370, 692-694. [CrossRef] [PubMed]

18. Niven, A. Rehabilitation adherence in sport injury: Sport physiotherapists' perceptions. J. Sport Rehabil. 2007, 16, 93-110. [CrossRef]

19. van Gool, C.H.; Penninx, B.W.; Kempen, G.I.; Rejeski, W.J.; Miller, G.D.; van Eijk, J.T.; Pahor, M.; Messier, S.P. Effects of exercise adherence on physical function among overweight older adults with knee osteoarthritis. Arthritis Rheum. 2005, 53, 24-32. [CrossRef]

20. Carvalho, E.; Bettger, J.P.; Goode, A.P. Insurance Coverage, Costs, and Barriers to Care for Outpatient Musculoskeletal Therapy and Rehabilitation Services. N. C. Med. J. 2017, 78, 312-314. [CrossRef]

21. Issa, K.; Naziri, Q.; Johnson, A.J.; Memon, T.; Dattilo, J.; Harwin, S.F.; Mont, M.A. Evaluation of patient satisfaction with physical therapy following primary THA. Orthopedics 2013, 36, e538-e542. [CrossRef]

22. Pivec, R.; Issa, K.; Given, K.; Harwin, S.F.; Greene, K.A.; Hitt, K.D.; Shi, S.; Mont, M.A. A prospective, longitudinal study of patient satisfaction following total knee arthroplasty using the Short-Form 36 (SF-36) survey stratified by various demographic and comorbid factors. J. Arthroplast. 2015, 30, 374-378. [CrossRef] [PubMed]

23. Westby, M.D.; Backman, C.L. Patient and health professional views on rehabilitation practices and outcomes following total hip and knee arthroplasty for osteoarthritis: A focus group study. BMC Health Serv. Res. 2010, 10, 119. [CrossRef] [PubMed]

24. Noble, P.C.; Gordon, M.J.; Weiss, J.M.; Reddix, R.N.; Conditt, M.A.; Mathis, K.B. Does total knee replacement restore normal knee function? Clin. Orthop. Relat. Res. 2005, 431, 157-165. [CrossRef] [PubMed]

25. Piva, S.R.; Moore, C.G.; Schneider, M.; Gil, A.B.; Almeida, G.J.; Irrgang, J.J. A randomized trial to compare exercise treatment methods for patients after total knee replacement: Protocol paper. BMC Musculoskelet Disord 2015, 16, 303. [CrossRef]

26. Friedrich, M.; Gittler, G.; Halberstadt, Y.; Cermak, T.; Heiller, I. Combined exercise and motivation program: Effect on the compliance and level of disability of patients with chronic low back pain: A randomized controlled trial. Arch. Phys. Med. Rehabil. 1998, 79, 475-487. [CrossRef]

27. Harkapaa, K.; Jarvikoski, A.; Mellin, G.; Hurri, H.; Luoma, J. Health locus of control beliefs and psychological distress as predictors for treatment outcome in low-back pain patients: Results of a 3-month follow-up of a controlled intervention study. Pain 1991, 46, 35-41. [CrossRef]

28. Reilly, K.; Lovejoy, B.; Williams, R.; Roth, H. Differences between a supervised and independent strength and conditioning program with chronic low back syndromes. J. Occup. Med. 1989, 31, 547-550. [CrossRef]

29. Piqueras, M.; Marco, E.; Coll, M.; Escalada, F.; Ballester, A.; Cinca, C.; Belmonte, R.; Muniesa, J.M. Effectiveness of an interactive virtual telerehabilitation system in patients after total knee arthoplasty: A randomized controlled trial. J. Rehabil. Med. 2013, 45, 392-396. [CrossRef]

30. Correia, F.D.; Nogueira, A.; Magalhaes, I.; Guimaraes, J.; Moreira, M.; Barradas, I.; Teixeira, L.; Tulha, J.; Seabra, R.; Lains, J.; et al. Home-based Rehabilitation With A Novel Digital Biofeedback System versus Conventional In-person Rehabilitation after Total Knee Replacement: A feasibility study. Sci. Rep. 2018, 8, 11299. [CrossRef] 
31. Kairy, D.; Tousignant, M.; Leclerc, N.; Cote, A.M.; Levasseur, M.; Researchers, T.T. The patient's perspective of in-home telerehabilitation physiotherapy services following total knee arthroplasty. Int. J. Environ. Res. Public Health 2013, 10, 3998-4011. [CrossRef]

32. Moffet, H.; Tousignant, M.; Nadeau, S.; Merette, C.; Boissy, P.; Corriveau, H.; Marquis, F.; Cabana, F.; Belzile, E.L.; Ranger, P.; et al. Patient Satisfaction with In-Home Telerehabilitation After Total Knee Arthroplasty: Results from a Randomized Controlled Trial. Telemed. e-Health 2017, 23, 80-87. [CrossRef] [PubMed]

33. Hussain, M.S.; Li, J.; Brindal, E.; van Kasteren, Y.; Varnfield, M.; Reeson, A.; Berkovsky, S.; Freyne, J. Supporting the Delivery of Total Knee Replacements Care for Both Patients and Their Clinicians With a Mobile App and Web-Based Tool: Randomized Controlled Trial Protocol. JMIR Res. Protoc. 2017, 6, e32. [CrossRef] [PubMed]

34. Fusco, F.; Turchetti, G. Telerehabilitation after total knee replacement in Italy: Cost-effectiveness and cost-utility analysis of a mixed telerehabilitation-standard rehabilitation programme compared with usual care. BMJ Open 2016, 6, e009964. [CrossRef]

35. Harmelink, K.E.M.; Zeegers, A.; Tonis, T.M.; Hullegie, W.; Nijhuis-van der Sanden, M.W.G.; Staal, J.B. The effectiveness of the use of a digital activity coaching system in addition to a two-week home-based exercise program in patients after total knee arthroplasty: Study protocol for a randomized controlled trial. BMC Musculoskelet Disord 2017, 18, 290. [CrossRef] [PubMed]

36. Fung, V.; Ho, A.; Shaffer, J.; Chung, E.; Gomez, M. Use of Nintendo Wii Fit in the rehabilitation of outpatients following total knee replacement: A preliminary randomised controlled trial. Physiotherapy 2012, 98, 183-188. [CrossRef] [PubMed]

37. Ficklscherer, A.; Stapf, J.; Meissner, K.M.; Niethammer, T.; Lahner, M.; Wagenhauser, M.; Muller, P.E.; Pietschmann, M.F. Testing the feasibility and safety of the Nintendo Wii gaming console in orthopedic rehabilitation: A pilot randomized controlled study. Arch. Med Sci. AMS 2016, 12, 1273-1278. [CrossRef] [PubMed]

38. Baltaci, G.; Harput, G.; Haksever, B.; Ulusoy, B.; Ozer, H. Comparison between Nintendo Wii Fit and conventional rehabilitation on functional performance outcomes after hamstring anterior cruciate ligament reconstruction: Prospective, randomized, controlled, double-blind clinical trial. Knee Surg. Sports Traumatol. Arthrosc. Off. J. ESSKA 2013, 21, 880-887. [CrossRef]

39. Prvu Bettger, J.; Green, C.L.; Holmes, D.N.; Chokshi, A.; Mather, R.C., 3rd; Hoch, B.T.; de Leon, A.J.; Aluisio, F.; Seyler, T.M.; Del Gaizo, D.J.; et al. Effects of Virtual Exercise Rehabilitation In-Home Therapy Compared with Traditional Care After Total Knee Arthroplasty: VERITAS, a Randomized Controlled Trial. JBJS 2020, 102, 101-109. [CrossRef]

40. Bell, K.M.; Onyeukwu, C.; McClincy, M.P.; Allen, M.; Bechard, L.; Mukherjee, A.; Hartman, R.A.; Smith, C.; Lynch, A.D.; Irrgang, J.J. Verification of a Portable Motion Tracking System for Remote Management of Physical Rehabilitation of the Knee. Sensors (Basel) 2019, 19, 1021. [CrossRef]

41. Irrgang, J.J.; Snyder-Mackler, L.; Wainner, R.S.; Fu, F.H.; Harner, C.D. Development of a patient-reported measure of function of the knee. JBJS 1998, 80, 1132-1145. [CrossRef]

42. Piva, S.R.; Gil, A.B.; Moore, C.G.; Fitzgerald, G.K. Responsiveness of the activities of daily living scale of the knee outcome survey and numeric pain rating scale in patients with patellofemoral pain. J. Rehabil. Med. 2009, 41, 129-135. [CrossRef] [PubMed]

43. Mockford, B.J.; Thompson, N.W.; Humphreys, P.; Beverland, D.E. Does a standard outpatient physiotherapy regime improve the range of knee motion after primary total knee arthroplasty? J. Arthroplast. 2008, 23, 1110-1114. [CrossRef] [PubMed]

44. Oak, S.R.; Strnad, G.J.; Bena, J.; Farrow, L.D.; Parker, R.D.; Jones, M.H.; Spindler, K.P. Responsiveness Comparison of the EQ-5D, PROMIS Global Health, and VR-12 Questionnaires in Knee Arthroscopy. Orthop. J. Sports Med. 2016, 4, 2325967116674714. [CrossRef] [PubMed]

45. Cesari, M.; Kritchevsky, S.B.; Newman, A.B.; Simonsick, E.M.; Harris, T.B.; Penninx, B.W.; Brach, J.S.; Tylavsky, F.A.; Satterfield, S.; Bauer, D.C.; et al. Added value of physical performance measures in predicting adverse health-related events: Results from the Health, Aging And Body Composition Study. J. Am. Geriatr. Soc. 2009, 57, 251-259. [CrossRef] 
46. Curb, J.D.; Ceria-Ulep, C.D.; Rodriguez, B.L.; Grove, J.; Guralnik, J.; Willcox, B.J.; Donlon, T.A.; Masaki, K.H.; Chen, R. Performance-based measures of physical function for high-function populations. J. Am. Geriatr. Soc. 2006, 54, 737-742. [CrossRef]

47. Hardy, S.E.; Perera, S.; Roumani, Y.F.; Chandler, J.M.; Studenski, S.A. Improvement in usual gait speed predicts better survival in older adults. J. Am. Geriatr. Soc. 2007, 55, 1727-1734. [CrossRef]

48. Freter, S.H.; Fruchter, N. Relationship between timed 'up and go' and gait time in an elderly orthopaedic rehabilitation population. Clin. Rehabil. 2000, 14, 96-101. [CrossRef]

49. Piva, S.R.; Schneider, M.J.; Moore, C.G.; Catelani, M.B.; Gil, A.B.; Klatt, B.A.; DiGioia, A.M.; Almeida, G.J.; Khoja, S.S.; Sowa, G.; et al. Effectiveness of Later-Stage Exercise Programs vs Usual Medical Care on Physical Function and Activity After Total Knee Replacement: A Randomized Clinical Trial. JAMA Netw. Open 2019, 2, e190018. [CrossRef]

50. Dabbs, A.D.V.; Myers, B.A.; Mc Curry, K.R.; Dunbar-Jacob, J.; Hawkins, R.P.; Begey, A.; Dew, M.A. User-Centered Design and Interactive Health Technologies for Patients. CIN Comput. Inform. Nurs. 2009, 27, 175-183. [CrossRef]

51. Epelde, G.; Carrasco, E.; Rajasekharan, S.; Jimenez, J.; Vivanco, K.; Gomez-Fraga, I.; Valencia, X.; Florez, J.; Abascal, J. Universal Remote Delivery of Rehabilitation: Validation with Seniors' Joint Rehabilitation Therapy. Cybern. Syst. 2014, 45, 109-122. [CrossRef]

52. Berg, J.; Dunbar-Jacob, J.; Sereika, S.M. An evaluation of a self-management program for adults with asthma. Clin. Nurs. Res. 1997, 6, 225-238. [CrossRef] [PubMed]

53. Dunbar-Jacob, J. Models for changing patient behavior. Am. J. Nurs. 2007, 107, 20-25. [CrossRef] [PubMed]

54. Dunbar-Jacob, J.; Erlen, J.A.; Schlenk, E.A.; Ryan, C.M.; Sereika, S.M.; Doswell, W.M. Adherence in chronic disease. Annu. Rev. Nurs. Res. 2000, 18, 48-90. [CrossRef] [PubMed]

55. Schlenk, E.A.; Dunbar-Jacob, J.; Engberg, S. Medication non-adherence among older adults: A review of strategies and interventions for improvement. J. Gerontol. Nurs. 2004, 30, 33-43. [CrossRef] [PubMed]

56. Schlenk, E.A.; Lias, J.L.; Sereika, S.M.; Dunbar-Jacob, J.; Kwoh, C.K. Improving Physical Activity and Function in Overweight and Obese Older Adults with Osteoarthritis of the Knee: A Feasibility Study. Rehabil. Nurs. 2011, 36, 32-42. [CrossRef]

Publisher's Note: MDPI stays neutral with regard to jurisdictional claims in published maps and institutional affiliations.

(C) 2020 by the authors. Licensee MDPI, Basel, Switzerland. This article is an open access article distributed under the terms and conditions of the Creative Commons Attribution (CC BY) license (http://creativecommons.org/licenses/by/4.0/). 